Valeria Giordano. Titular del Dipartimento di Scienze Giuridiche de la Università degli Studi di Salerno. Enseña Teoría General del Derecho y Teoría del Derecho y de la Argumentación. Es autora de Il positivismo e la sfida dei principi, Napoli, 2004, y de Modelli argomentativi delle teorie giuridiche contemporanee, Napoli, 2008. Entre sus últimas publicaciones sobre positivismo jurídico, interpretación de los derechos constitucionales y la globalización jurídica, se encuentran: "Justification et Force en droit: Una dicotomie irreductible?" in J.F. Kervégan, M. Plouviez, P. Y. Quivigev (eds.) Norme et violence, Olms, Verlag, Hildesheim, Zürich-New York, 2015, pp. 41-54. "Pluralismo de los valores y neutralización jurídica”, en Soft Power. Revista euro-americana de teoría e historia de la política, vol. 2, 2014, pp.124-146.

Contacto: vgiordano@unisa.it 


\title{
SOFT Y HARD POWER: ¿COEXISTENCIA O CONFLICTO DE PARADIGMAS?
}

\author{
Valeria Giordano
}

Università degli Studi di Salerno

\section{SOFT AND HARD POWER. COEXISTENCE OR CONFLICT BETWEEN PARADIGMS?}

DOI : 1017450/160101

Este número de Soft Power nace de la Conferencia -con el mismo título- organizada con ocasión de la presentación de la revista el 22 y 23 de septiembre de 2015 en la Università degli Studi di Salerno. Está dedicado a la pluralidad de formas que hoy día tiene el poder, a la relación oscura y al vínculo ambiguo existente entre soft y hard power. Se trata, pues, de una dialéctica que se desarrolla en un debate teórico, empezado a finales de los años noventa, en el que parecen influir mucho -en su reflexión filosófico-política- las diferentes concepciones de "poder", así como las ambigüedades que atañen a los confines, a las definiciones de las dos diferentes tipologías.

Tradicionalmente, la prevalencia del empleo del poder político-militar respecto de un poder persuasivo y seductor resulta ser el elemento que fundamenta la contraposición teórica: esto es, una contraposición que, a pesar de expresar diferentes modalidades 
de orientación a la acción y diversas formas de autoridad política, representa de forma dualista la fisonomía del poder en la génesis de un nuevo paradigma.

Se trata de la doble cara del poder que Joseph Nye detectó en las técnicas políticas estadounidenses y en el atractivo de su modelo cultural, para convertirlas en el aspecto complementario del hard power, el poder duro, simétrico, que reproduce una lógica retributiva. En cambio, la otra cara de Jano es suave, flexible, difundida, capaz de modelar las preferencias de los demás, basándose en la mezcla de las opciones iniciales y volviendo a determinar la prioridad de las elecciones, moviéndose en el ámbito de la seducción y de la cooptación. Por lo tanto, es soft.

Es soft porque se estructura en la red de las relaciones internacionales y condiciona a los actores de la escena global a través de técnicas de atracción positiva que plasman el contexto en el que actúan Estados e instituciones, extendiendo sus efectos por medio del empleo de recursos diferentes a los que, tradicionalmente, se emplean en la orientación/control de los comportamientos sociales. Sin embargo, su dimensión relacional, basada en valores, políticas, cultura -en lugar de elementos coercitivos-, implica una lógica económica y, por ende, una racionalidad estratégica. De ahí que racionalidades heterogéneas y nuevos dispositivos de poder se produzcan en el ámbito de la globalización, gracias a políticas de origen liberalista y al progresivo proceso de erosión de las soberanías estatales, para generar nuevos arquetipos de mediación política.

Está claro que las profundas transformaciones de las sociedades actuales, cada vez más caracterizadas por dinámicas de variabilidad e incertidumbre y por muchas contradicciones que conllevan el desplazamiento de la producción normativa incluso por fuera de las tradicionales geometrías político-jurídicas, se graban de forma contradictoria sobre los criterios de legitimidad de los poderes en la nueva configuración de la gobernanza global, destacando la exigencia de una mirada teórica capaz de sondear los múltiples matices de aquellos dispositivos soft y hard que nacen de la fragmentación social.

El número de la revista empieza con una pregunta crucial que atañe al destino de la soberanía política: ¿El soft power es la forma definitiva de gobernanza del capitalismo?

Sin duda, es necesario sacar provecho del potencial innovador de la historia, considerando al capitalismo como una realidad, un hecho histórico sobrevenido y no pedido (Villacañas); empleando el sistema conceptual weberiano y aquella lógica reflexiva, procesual, adecuativa, por medio de la cual desaparecen las tensiones entre el capital financiero, el capital industrial y el capital humano, y se revaloriza -desde un punto de vista totalmente diferente- la compleja tradición del humanismo práctico (Guadarrama), 
sobre todo su corriente latinoamericana para el desarrollo de los derechos humanos y de la democracia.

Sin embargo, puesto que los itinerarios históricos siempre son contradictorios, probablemente no es necesario contar una historia nueva, sino volver a escribir la trama de los regímenes democráticos y representativos (Mastropaolo), despojándolos de la maravillosa retórica que los caracteriza y enseñando su dosis controlada de conflicto y de desorden volcada en los que detienen el poder en el Estado. Aquel conflicto atañe precisamente a la relación entre Estado y legalidad, entendida como legalität o légalité, es decir, el alma, el soplo vital de la sociedad burguesa; no se trata de un alma jurídica, porque el derecho es el remedio solo cuando "la insociable sociabilidad" de la sociedad burguesa supera un nivel fisiológico de conflictividad (Riccobono).

Es un punto de vista crítico que pone de manifiesto cómo las metamorfosis del principio de legalidad presentan elementos fundamentales, comenzando por el de la certeza del derecho en un sistema de fuentes ya no totalmente jerarquizado y vertical, sino dentro de una red horizontal de materiales normativos que los intérpretes siguen adaptando y suscitando preguntas cruciales sobre lo que queda del valor político de la légalité o de la ambición jurídico-social de la gesetzlichkeit.

Está claro que el valor político-simbólico de lo social sirve para legitimar el poder y para que haya un cambio contra el riesgo de una valorización ideológica de los dispositivos de dominio neoliberalistas, que gozan de la declarada falta de alternativas, es decir, intrascendibilidad (Preterossi) y se necesitaría de un nuevo imaginario que no se olvide del vínculo sutil y nunca neutralizable que existe entre el poder y lo sagrado, pues es el marco religioso o metafísico -más o menos secularizado- de toda institución social.

La inmanencia de la racionalidad política neoliberal proporciona escenarios nuevos y diferentes de estudio y de investigación que se cruzan en el ámbito del análisis de los cambios epocales de los sistemas político-jurídicos frente al desafío lanzado por el mercado, por su racionalidad neogubernamental o por una teología económica, interpretada en términos de teología política disimulada (Preterossi) que, de todas formas, dificulta la relación entre poder-Estado en la gobernanza global, tal y como en el ciberespacio (Amoretti-Santaniello), dentro del cual emergen complejas relaciones de poder y el desarrollo de conflictos políticos en la red global (del IAHC al WSIS, hasta los más recientes procesos como el WCIT y el NetMundial) difíciles de gestionar y solucionar.

Sin duda, los procesos de globalización representan el motor de una gran revolución que deja muchos interrogantes acerca del destino del derecho y exige -en un cuadro cada vez más fragmentado y menos rigurosamente ordenado- una redefinición de aquellas 
categorías centrales sobre las que la ciencia jurídica tradicional ha puesto los cimientos de la racionalidad jurídico-política moderna. La ampliación del poder decisional de las cortes, que resulta ser fundamental para la evolución del derecho transnacional y que presenta una gran predisposición teórica a leer el derecho de inclinación global como razonamiento jurídico, de manera progresiva da lugar a itinerarios variados y a modalidades de reglamentación jurídica cada vez más cercanas a los tipos angloamericanos del judge made-law, por lo que desarrolla en el mundo global una función de institucionalización del conflicto en una perspectiva de creciente procedimentación de los sistemas jurídicos. Esta perspectiva necesita volver a considerar la problemática del reconocimiento del derecho, desde el punto de vista de la nueva sistematización de las fuentes y con respecto al razonamiento moral substantivo y a las nuevas declinaciones del nexo autoridad-soberanía, cuya crisis parecería arreglarse a través de la racionalidad práctico-dialógica de la jurisprudencia.

De ahí que racionalidades heterogéneas se fusionen en la dimensión transnacional en un proceso lleno de contradicciones que resalta la marca procesal de la técnica jurídica, llevando a perspectivas práctico-argumentativas que revalúan los criterios de universalidad y congruencia en los procesos decisionales, y que -sobre todo desde el punto de vista clínico y bioético (Seoane)- destacan el carácter imprescindible de una síntesis entre hechos, valores, normas, procedimientos deliberativos, que funcionen desde el punto de vista de la justificación práctica.

Además, en el cruce que cada vez más se da entre nacional y global, dentro de los mecanismos de una red policéntrica pero nunca definitiva, estas presentan inéditas y flexibles modalidades de reglamentación jurídica -como, por ejemplo, la soft law-, formas híbridas de normatividad (Giordano) que revelan, en el ámbito de la teoría jurídica, la coexistencia y el conflicto entre prácticas, políticas y saberes.

Es el encuentro-choque entre los diferentes regímenes el que ocupa el panorama contemporáneo, animando un contexto enigmático y lleno de asimetrías y ambigüedades en la superposición de nuevos léxicos, categorías tradicionales y formas de juridicidad controvertida. Así que volver a semantizar no es un desafío nada fácil, pero sí indispensable para un léxico que cada vez más se enfrenta a las dificultades de la articulación entre los poderes globales y las caras contradictorias de la efectividad del derecho hoy día, que radicalizan su polisemia (Riccobono, Pitch, Giordano) y tienden a generar una presión contradictoria sobre los conceptos jurídicos.

De hecho, si viejos y nuevos lenguajes se cruzan, intentando contestar interrogantes y dilemas oscuros derivados de la fragmentación de un universo jurídico cada vez más 
caracterizado por "mónadas autosuficientes que se comunican entre ellas en la base de formas indeterminadas y casuales" (Riccobono), entonces, ¿qué es lo que está dentro y lo que se queda fuera del derecho?

El residuo entre la factibilidad de prácticas transnacionales cada vez más difundidas y vinculantes y la tentativa de una formalización jerárquica del dispositivoderecho tiene confines precarios y márgenes que siempre tienden a desvanecerse en la cartografía del soft power, en el que la problemática de la ciudadanía, el tema criminal y la perspectiva de género se mezclan con la difusión de las políticas dirigidas a la protección de la seguridad, volviendo a trazar sus confines y la cada vez más creciente demanda a nivel nacional/local de seguridad que, con el aumento de flujos, mercancías y personas, se hace cada vez más necesaria hasta volver a definir la misma categoría jurídica de crimen (Pitch).

Se trata de discursos, políticas y dilemas que la gubernamentalidad neoliberal deja pendientes y que convierten en complejo e interesante el desafío de los estudiosos.

Traducción del italiano de M. Colucciello 